\title{
Reinstating the Humanities in the Digital Age
}

\author{
Lipika Kankaria \\ Junior Research Fellow \\ National Institute Of Technology, Durgapur, India
}

\begin{abstract}
The significance of studying Humanities is constantly being questioned in the increasingly digitalized world. The issue that I wish to discuss/address in this paper is what is wrong with our perception of the Humanities - their methods and their purpose - both within and outside the academia. The question of the development of the mind is pushed to the periphery in the consumeristic world, where we are being told what to do from various agencies like the political parties, government, etc. The scholars from the humanities department have to assert why research needs to be conducted in these areas. We fail to emphasize the importance of humanistic research - research that does not depend solely on data and hard evidence to reach conclusions but employs methods that are analytical and interpretative in nature. We lack the conviction to say that uncovering new meanings in literary texts and finding new ways to understand cultural interactions helps us re-imagine our past, offers significant insights into our present and provides clarity about our future. The field of Humanities has not been untouched by the development in technology but that has not reduced the importance of the study of Humanities. Newer avenues have opened up like Digital Humanities and also archives and research work is made available to all across the world which is the result of a synthesis between the traditional study of humanities and the current trends of technology.
\end{abstract}

